\title{
Numerical simulation of flood barriers
}

\author{
Pavel Srb ${ }^{1, *}$, Michal Petrů ${ }^{1}$, and Petr Kulhavý ${ }^{1}$ \\ ${ }^{1}$ Institute for Nanomaterials, Advanced Technologies and Innovation, Technical University of Liberec, Studentská 2 , \\ 461 17, Liberec 1, Czech Republic
}

\begin{abstract}
This paper deals with testing and numerical simulating of flood barriers. The Czech Republic has been hit by several very devastating floods in past years. These floods caused several dozens of causalities and property damage reached billions of Euros. The development of flood measures is very important, especially for the reduction the number of casualties and the amount of property damage. The aim of flood control measures is the detention of water outside populated areas and drainage of water from populated areas as soon as possible. For new flood barrier design it is very important to know its behaviour in case of a real flood. During the development of the barrier several standardized tests have to be carried out. Based on the results from these tests numerical simulation was compiled using Abaqus software and some analyses were carried out. Based on these numerical simulations it will be possible to predict the behaviour of barriers and thus improve their design.
\end{abstract}

\section{Introduction}

Floods in terms of their occurrence are inseparable, spatially and temporally irregular part of the water cycle. Its erosion, sedimentation, transports, mechanical and other effects are an important element of landscape development process [1].

According to the European directive [2], the term "flood" means the temporary covering by water of land not normally covered by water. This shall include floods from rivers, mountain torrents, Mediterranean ephemeral water courses, and floods from the sea in coastal areas, and may exclude floods from sewerage systems.

The term "flood risk" means the combination of the probability of a flood event and of the potential adverse consequences for human health, the environment, cultural heritage and economic activity associated with a flood event.

In the Czech Republic there are floods caused especially by torrential rains, prolonged rains, melting snow and moving of ice floe. In 1997 the Czech Republic was hit by flood, whose size and damaging impact was surprising [3]. The flood of a comparable size had not affected the Czech Republic perhaps in several centuries. Nobody could have expected that there would be a flood of similar magnitude over a very short period of several years. Since 1997 the Czech Republic has been hit by several other very devastating floods. Both loss of life and material damage are shown in table 1.

These recent floods disproved the myth that from natural point of view the next large flood can be expected in the longer period of time. Further flood can be expected at a distance of few years. Documented historical floods in the territory of the Czech Republic from eg. 1890, 1897 and 1903 demonstrate that the grouping of flood in a shorter period of time is not so unusual.

Table 1. Loss of life and material damage [4]

\begin{tabular}{|c|c|c|}
\hline Year & Loss of lives & Damage [mil. CZK] \\
\hline 1997 & 60 & 62,600 \\
\hline 1998 & 10 & 1,800 \\
\hline 2000 & 2 & 3,800 \\
\hline 2001 & 0 & 1,000 \\
\hline 2002 & 19 & 75,100 \\
\hline 2006 & 9 & 6,200 \\
\hline 2009 & 15 & 8,500 \\
\hline 2010 & 8 & 15,200 \\
\hline 2013 & 15 & 15,400 \\
\hline
\end{tabular}

Floods in the Czech Republic has always occurred, and therefore we must reckon with them in the future also. Each flood is different, formation mechanisms of same type of flood may be similar, but the course and effects on the environment are unique. Follows from the foregoing it is necessary to learn and expand our knowledge and experience from previous floods, for reduction of life lost and damage caused by future floods $[5,6]$.

\footnotetext{
Corresponding author: pavel.srb@,tul.cz
} 


\section{Flood barriers}

There are many requirements on flood barriers and their components [7]. All materials used in flood abatement equipment shall be suitable for the intended application. Flood abatement equipment have to be constructed using corrosion resistant materials. The materials used for the seals must be resistant to biological degradation. Manually operated caps and valves, and mechanisms, must have a securing, locking, and supervising component. The design of automatic opening barriers shall be such that major debris that could impact the barrier's functionality is prevented from entering the system. Other debris shall be able to be flushed from the system during periodic maintenance. All components of the flood abatement equipment products need to be regularly tested. The components required for the flood abatement equipment shall be designed for proper system functionality, and maximum long term reliability. Flood abatement equipment designs should take into account the possibility of component failure and the potential of that failure to impair the effectiveness of the system. Such impairments shall be minimized through fail-safe, redundant component, over-design, de-rating, or other means demonstrating equivalent reliability.

Figure 1. shows one typical design of flood barrier with ground structure. This barrier contains 2 portable pillars, several stop logs and tightening devices. The portable pillars are aluminium $\mathrm{H}$-shaped poles which stop logs are inserted into. The stop logs are hollow extruded profiles with sealing in the bottom.

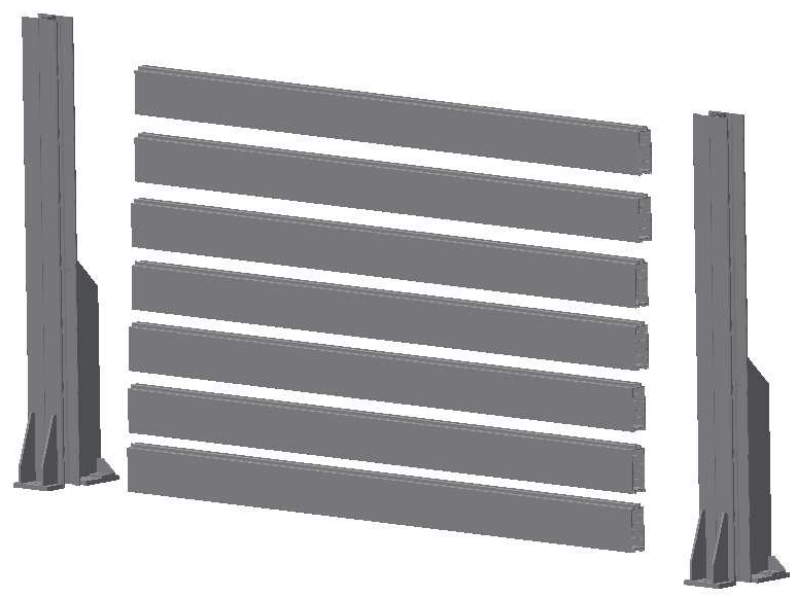

Fig. 1. Flood barrier design.

\section{Barrier testing}

Flood barriers must be subjected to many tests like hydrostatic strength test, system leakage, vibration resistance, impact and wear resistance, salt spray corrosion and many others. Performance testing on components may be conducted for an individual component, component assembly and also for the entire barrier system. This paper focuses especially on the debris impact test. A flood barrier should withstanding multiple impacts from floating debris. The leakage rate shall not exceed 3.1 litres per minute per meter length. The barrier's length is measured along centre point of the barrier's seal to the ground. In addition, the permanent deflection of the barrier shall be less than or equal to $15 \mathrm{~cm}$. Limit water level should be $2 / 3$ of maximum water depth. Two tests shall be conducted with two different size logs of diameter 30 and $43 \mathrm{~cm}$, weight 277 and $358 \mathrm{~kg}$.

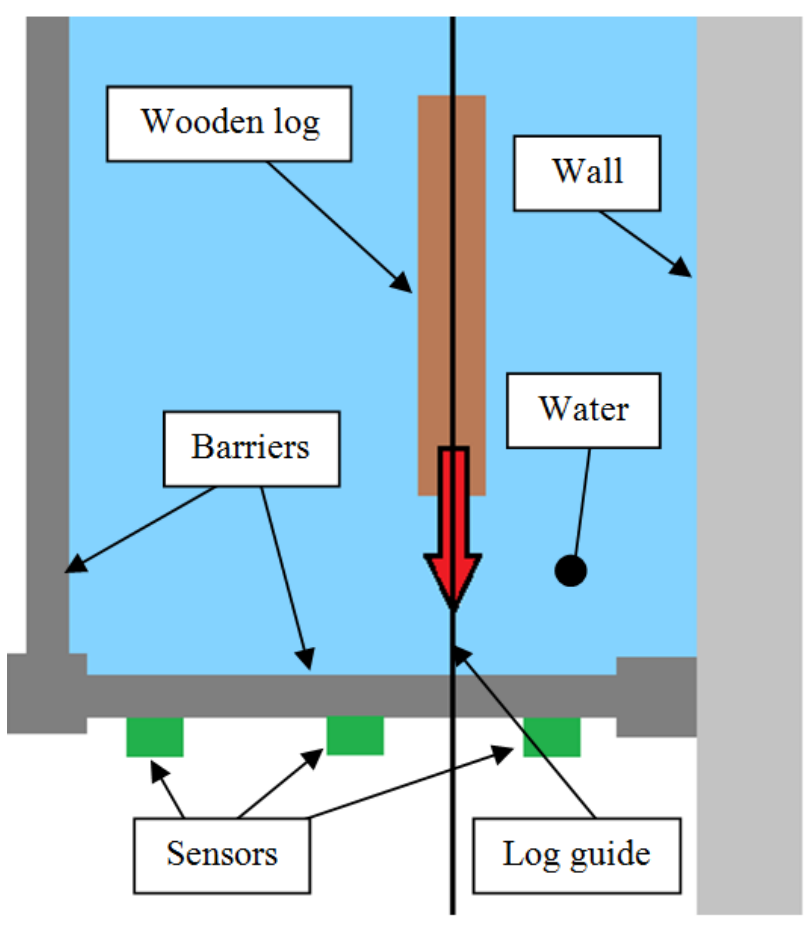

Fig. 2. Layout of experiment

The experiment [8] (Fig. 2 and 3) was assembled in hydrodynamic laboratory at a company called JAPJacina in the best possible accordance to the standard [7]. Impact test was conducted by impactor (wooden $\log$ ) several times at speed rating from 0.2 to $2 \mathrm{~m} . \mathrm{s}^{-1}$.

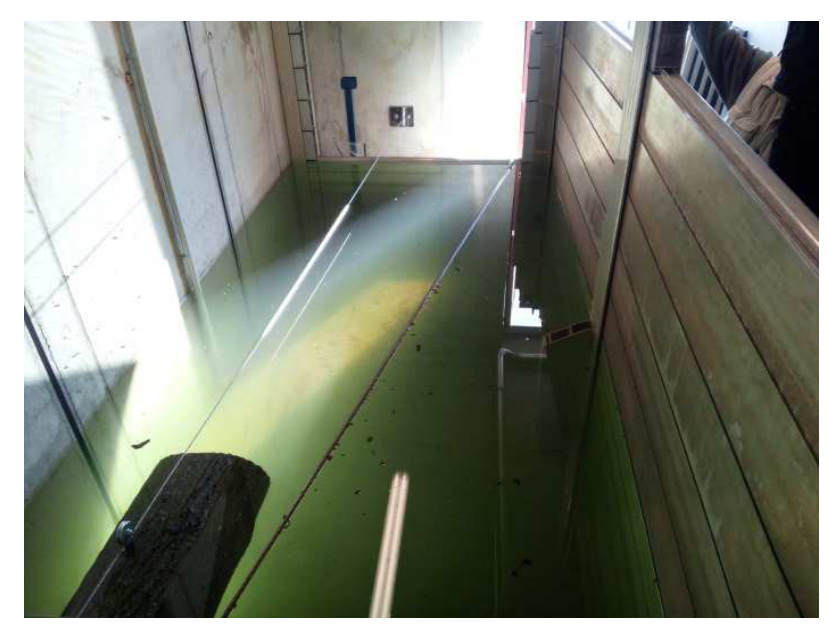

Fig. 3. Real assembly of experiment.

The whole testing process was measured by system DEWETRON DEWE 500. The measured values provided information of barrier displacements in three 
positions, deformation of the barrier by tensometer and movement of the wooden $\log$ by wire displacement sensor. Acquired data including the synchronized with a high speed video camera were recorded to measuring device. The maximum deflection value of flood barrier at the moment of impact was determined as the difference of values in the centre sensor and corner sensors. This consideration is based on the assumption that the corner sensors measure the deformation of the rubber seal in the anchoring pillars. This approach eliminates the deformation of the seal, and shows the actual deflection of the barrier.

\section{Numerical simulations}

A problem involving fluid flow interaction with structures is called fluid-structure problem (FSI), for example, the flow around a structure interacting with the structure and vice versa. The flow usually undergoes large deformation, but the structure does not have to be fixed and rigid but can be moveable and deformable [9]. Examples are sloshing of tanks in launchers, limit cycle oscillations of wings or instabilities in the wind interaction with cable stayed bridges.

\subsection{CEL method}

Coupled Eulerian Lagrange Analysis technique combines two mesh approaches Lagrangian and Eulerian in one analysis $[9,10]$. This method was developed initially for the simulation of the inflation of an airbag, and then followed problems like tank sloshing due to impact loads, collisions between a bird and aircraft and aquaplaning.

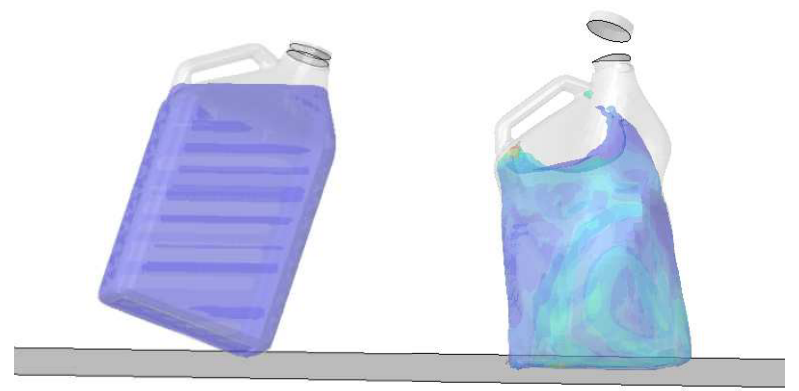

Fig. 4. The water-filled bottle drop test.

The example of CEL simulation is shown in Fig 4. there is the result of the water filled bottle drop test [11]. The bottle hit the floor at a skew angle, with one of the bottom corners experiencing the initial impact. A simulation for the bottle accounts both the exterior forces on the bottle from the floor impact, as well as the interior forces of the water pushing against the bottle.

This method consists of mesh treatment, surface reconstruction and solving fluid and structure equations. The purpose of this technique is to avoid mesh problems when performing simulations that involve extreme deformations. The most common mesh approach is the Lagrangian one, but that is not suitable for excessive distortion cases. For those cases Eulerian meshing approach is more suitable. CEL technique captures the strengths of both Lagrangian and Eulerian methods.

The CEL method enables the user to selectively mesh the analysis components. The large deformed bodies (fluid, gas, etc.) can be meshed using Eulerian technique and remaining moving structure using the conventional Lagrangian technique. The interaction behavior between them is given by contact definition

In Lagrangian simulations each element of the mesh is used to represent a volume of material. The material move is possible only with mesh deformation. The Lagrangian approach is suitable for the majority of structural problems, but in simulations where the material is under large deformations, elements will become distorted and the simulation cannot continue. Figure 5 shows the Lagrangian simulation, on the left undeformed object, on the right deformed object.
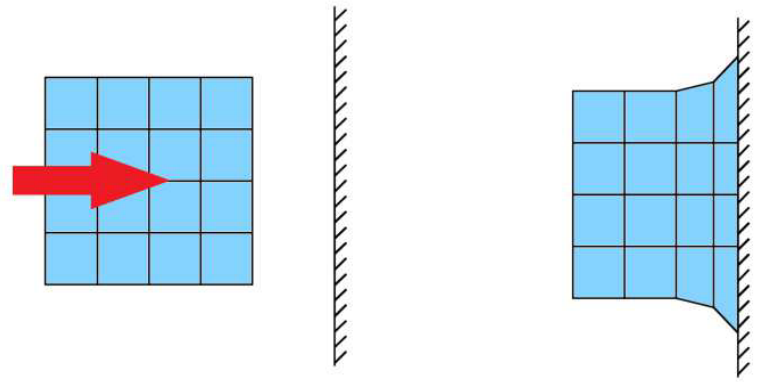

Fig. 5. Lagrangian simulation

In Eulerian simulations, the grid remains stationary during the simulation and material flows through elements that do not deform. The Eulerian mesh is typically a simple rectangular grid of elements constructed to extend well beyond the Eulerian material boundaries, giving the material space to move and deform. Figure 6 shows Eulerian simulation, the initial shape on the left and the deformed one on the right.
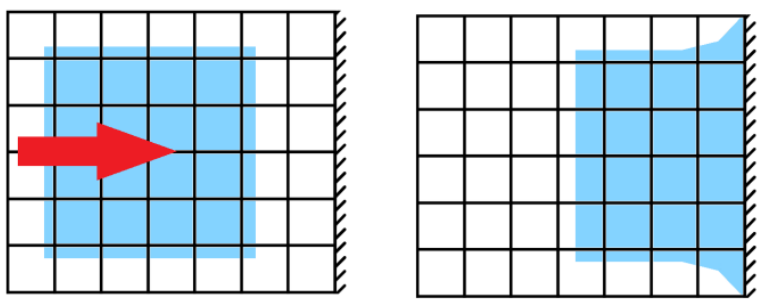

Fig. 6. Eulerian simulation

\subsection{Assigning materials}

For assigning material in Eulerian analysis it is necessary to use an assignment predefined field. Material assignment predefined fields rely on the concept of material volume fractions. During an Eulerian analysis there is a tracked material presentation in each element in terms of a volume fraction. The volume fraction represents the percentage of the element's volume that is occupied by a given material. For elements that are partially filled with material the exact geometric 
composition of the material within the element is not known. Abaqus interpolates the material volume fractions from adjacent elements to estimate the material boundaries within the element. Volume fractions are expressed as a number between zero and one, this number means the percentage of filling, e.g. 0.32 means that $32 \%$ of element is filled by assigned material. Figure 7 shows an example of a volume fraction.

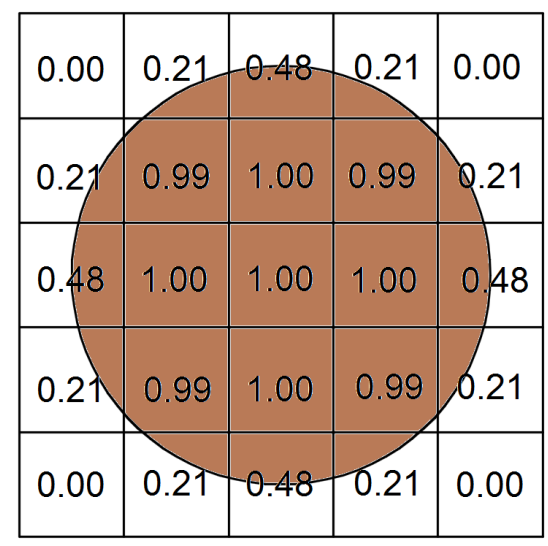

Fig. 7. Volume fraction example.

The elements where volume fractions are not defined were assigned as a void. Similarly, for the elements where volume fraction is less than one, a void is assigned for remainder of the volume fraction. The void elements do not have material properties, but other material can flow into and through void elements during the analysis.

\subsection{Material model of water}

Formulation of Equation of state Mie Grüneisen $U_{S}-U_{P}$ form [9, 10] was used as a material model for water in the Abaqus simulation. The most common form of MieGrüneisen is:

$$
p-p_{H}=\Gamma \rho\left(E_{m}-E_{H}\right)
$$

where $p_{H}$ and $E_{H}$ are the Hugoniot pressure and specific energy (per unit mass) and they are functions of density only. $\Gamma$ is the Grüneisen ratio, which describes the alteration in a crystal lattice's vibration frequency, based on the lattice's increase or decrease in volume as a result of temperature change. It is used in quantum mechanics and it is defined as:

$$
\Gamma=\Gamma_{0} \frac{\rho_{0}}{\rho}
$$

Where $\Gamma_{0}$ is the initial Grüneisen ratio (material constant) and $\rho_{0}$ is the reference density. The Hugoniot energy $\mathrm{E}_{\mathrm{H}}$ is related to the Hugoniot pressure $\mathrm{p}_{\mathrm{H}}$ by:

$$
E_{H}=\frac{p_{H} \eta}{2 \rho_{0}}
$$

Where $\eta=1-\rho_{0} / p$ is the nominal volumetric compressive strain. Elimination of $\Gamma$ and $E_{H}$ from the above equations yields:

$$
p=p_{H}\left(1-\frac{\Gamma_{0} \eta}{2}\right)+\Gamma_{0} \rho_{0} E_{m}
$$

The state and the energy equations represent coupled equations for pressure and internal energy. Abaqus solves these equations simultaneously at each material point.

A common form of the Hugoniot data is given by

$$
p_{H}=\frac{\rho_{0} c_{0}^{2} \eta}{(1-s \eta)^{2}}
$$

Where $\mathrm{c}_{0}$ and $\mathrm{s}$ define the linear relationship between the shock velocity $U_{S}$ and the particle velocity $U_{P}$ as follows:

$$
U_{S}=c_{0}+s U_{p}
$$

With the above assumptions the linear $\mathrm{U}_{\mathrm{S}}-\mathrm{U}_{\mathrm{P}}$ Hugoniot form is written as

$$
p=\frac{\rho_{0} c_{0}^{2} \eta}{(1-s \eta)^{2}}\left(1-\frac{\Gamma_{0} \eta}{2}\right)+\Gamma_{0} \rho_{0} \mathrm{E}_{\mathrm{m}}
$$

Where

$$
\rho_{0} c_{0}^{2}>0
$$

is equivalent to the elastic bulk modulus at small nominal strains. There is a limiting compression given by the denominator of this form of the equation of state

$$
\eta_{\text {lim }}=\frac{1}{s}
$$

or

$$
\rho_{\text {lim }}=\frac{s \rho_{0}}{s-1}
$$

In case of modeling water according to [10] the parametres given by table 2 were used.

Table 2. Parameters used for material model

\begin{tabular}{|c|c|}
\hline Parameter & Value \\
\hline Density $(\rho)$ & $1,000 \mathrm{~kg} / \mathrm{m}^{3}$ \\
\hline Viscosity $(\eta)$ & $0.001 \mathrm{~Pa} \mathrm{~s}$ \\
\hline $\mathrm{C}_{0}$ & $1483 \mathrm{~m} / \mathrm{s}$ \\
\hline $\mathrm{s}$ & 0 \\
\hline$\Gamma_{0}$ & 0 \\
\hline
\end{tabular}

\subsection{Model definitions}

A simplified CAD model of flood barriers was used to define the numerical simulation. The real flood barrier contains two portable pillars, a certain number of stop logs depending of on the height of the whole barrier and tightening device. For the simulation the entire barrier was replaced by only two horizontal stop logs formed by the rectangular hollow profile with a length of $1.2 \mathrm{~m}$ and wall thickness of $3 \mathrm{~mm}$. The other stop logs have minimal effect on the experiment therefore can be neglected. The effect of fixed pillars was replaced with fixed constraints to both ends of used stop logs. Eulerian 
volume (where water can move) was created as a block of $5 \times 1 \times 0.5 \mathrm{~m}$. The initial volume of water formed by the block $4 \times 1 \times 0.35 \mathrm{~m}$ was placed to Eulerian volume. a log with a diameter of $0.2 \mathrm{~m}$ and $3 \mathrm{~m}$ length with a density of $900 \mathrm{kgm}^{-3}$ (weight $85 \mathrm{~kg}$ ), which corresponds approximately to the $\log$ used in real experiment, was placed into the water area. The assembly of the simulation is shown in Figure 8.

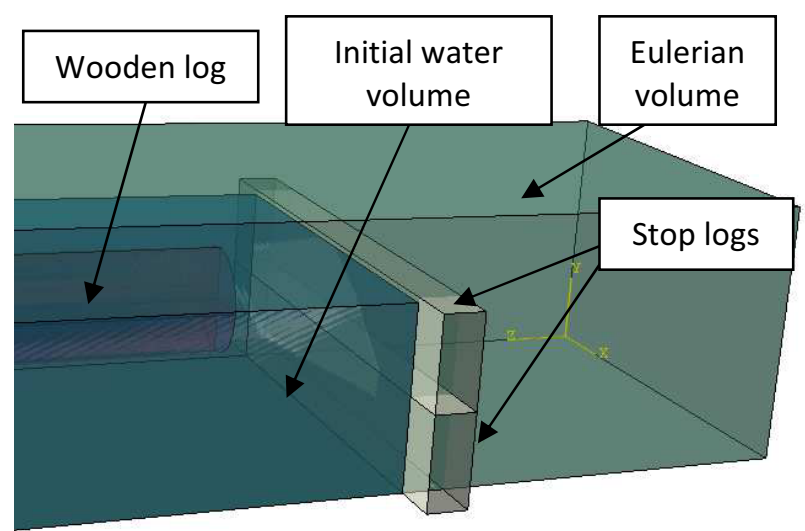

Fig. 8. Assembly of simulation.

The mesh used in the simulation was quite coarse. The Eulerian volume was meshed by 32,500 brick elements with edge size $40 \mathrm{~mm}$, the wooden log contains 1,200 brick elements with the shortest edge $28.4 \mathrm{~mm}$ and the stop log contains 240 shell quad elements with edge lenght $40 \mathrm{~mm}$.

The gravitational acceleration of $9.81 \mathrm{~ms}^{-2}$ was applied on the whole assembly. The log movement was controlled in order to reach desired speed (from 1 to $2 \mathrm{~ms}^{-1}$ ) during $1 \mathrm{~s}$, after that the forced move was deactivated and the log was moved its own momentum. The entire simulated action lasted about 2 seconds, depending on the speed of the log.

Explicit method and CEL technique is intended primarily for fast processes lasting usually in the order of milliseconds. In this case where the length is about $2 \mathrm{~s}$ problem with contact stability between water and structure may occur.

Volume fraction information on the nodes is determined by the arithmetic mean of the volume fraction values of the cell surrounding the considered node. When volume fraction value on the node is under 0.5 , the contact of fluid and structure is not applied on this node. The liquid may penetrate into the Lagrangian body. Leaking problem is self-recovering. Once it is leaking into nearby node with low volume fraction thus leading to increased mean of volume fraction in the surrounding cells. Once the value of the volume fraction rises to 0.5 on node, contact is applied again. This recapture of contact may result in rapid displacement of liquid which cause unrealistic acceleration of liquid.

\section{Results}

The simulation was carried out in the first place to see whether it is even possible to simulate water in such spatial and time range. From a visual comparison of animation of simulation results and the record of high speed camera it can be concluded that both waveforms are very similar. Figures 9 and 10 show the behavior of water just before impact of the log in the simulation and real experiment.

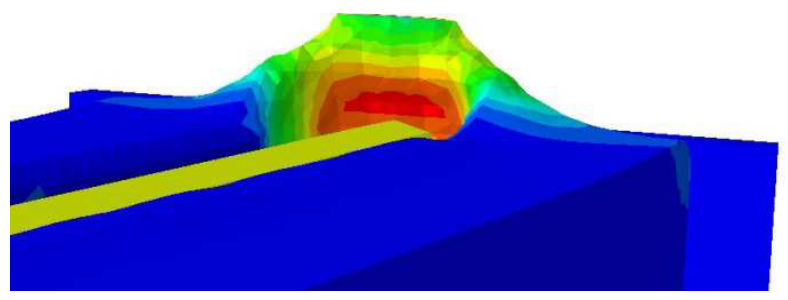

Fig. 9. Shape of water splash - simulation.

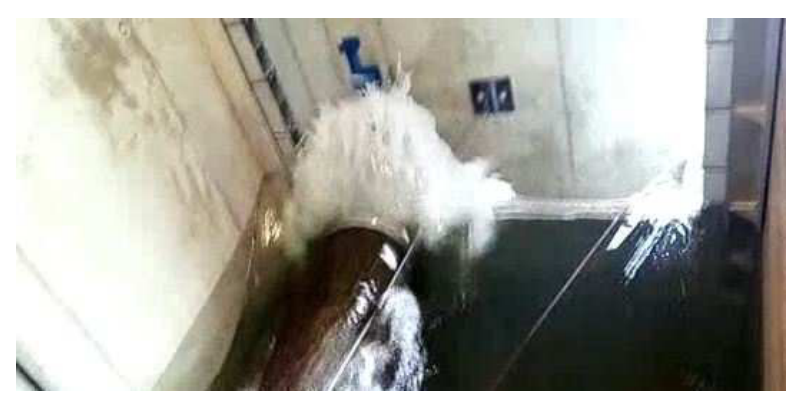

Fig. 10. Shape of water splash - experiment.

It can be said that the shape of the splashed water in the simulation is relatively in good agreement with the real experiment. The next question is about precision of simulation results. In Figure 11 shows the results of deformation distribution of the stop logs affected by the wooden $\log$.

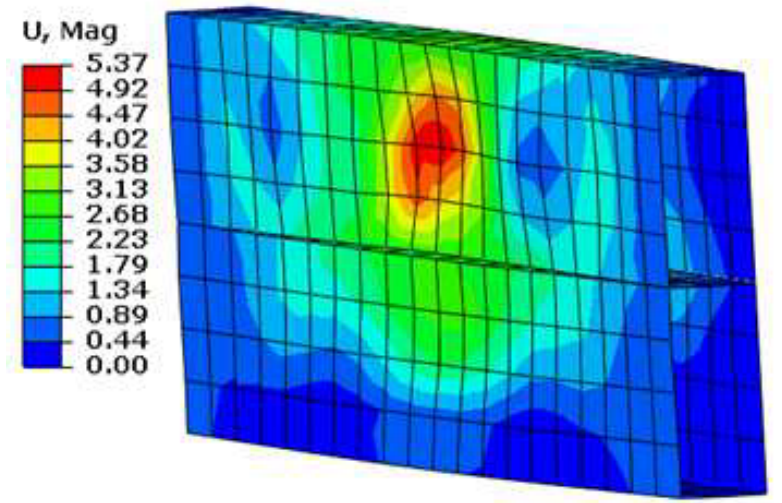

Fig. 11. Maximal deformation of stop log.

The maximal value of deformation in the simulation was about $5.4 \mathrm{~mm}$, in the experiment under the same conditions it was $4.6 \mathrm{~mm}$. Both values are in a quite good agreement considering the simplifications of the simulation.

\section{Conclusion}

In the case of a flood, it is necessary to ensure the protection of people and property as soon as possible. One of possibilities is using mobile flood barriers. Mobile barriers must fulfil many requirements, such as low weight, easy installation, durability, low price etc. All these requirements must considered for a 
development of a new design of flood barrier. During a development, it is therefore necessary to carry out many tests, which are often very expensive. Some of these tests can be replaced by numerical simulations. Numerical simulations were performed using Abaqus software by CEL (Coupled Eulerina Lagrangian) technique. The results of the simulations of simplified models show a relatively good agreement with experiments. Thus proving that numerical simulations are a good auxiliary tool in examining the behaviour of water interacting with the flood barrier. The numerical simulations can be used to predict the behaviour of the barrier during a flood, which is very important but hardly feasible by experiment.

In future work, similar simulations will be used in the development and optimization of new types of flood barriers without ground structure.

\section{Acknowledgements}

The results of this project VI20152018005 were obtained with co-funding from the Ministry of the Interior of the Czech republic as part of targeted support from the project "Vývoj protipovodňových systémů pro zvýšení ochrany obyvatelstva a infrastruktury".

\section{References}

1. J. Hladný, Sbornik príspěvků závěrečného semináře Hodnocení vlivu změn př́rodního prostředi na vznik a vývoj povodní, Fakta a mýty o povodnich. (2007)

2. Official Journal of the European Union, Directive 2007/60/ec, 288, 27, (2007)

3. J. Hladný, et al, Vyhodnocení povodñové situace $v$ červenci 1997, Souhrnná zpráva, (1998)

4. P. Puncochar, Flood protection in the czech republic and international, Anti flood defenses today's problems, (2012)

5. J. Hladný, M. Kratka, L. Kašpárek, August 2002 catastrophic flood in the Czech Republic (2004)

6. L. Čamrová, J. Jílková, Povodňové škody a nástroje k jejich snižení. (2006)

7. Approval Standard for Flood Abatement Equipment, Class Number 2510, FM Approvals LLC. (2013)

8. M. Petrů, L. Ševčík, A. Lufinka, T. Martinec, EAN, 54, (2016)

9. A. Sillem, Feasibility study of a tire hydroplaning simulation in a finite element code using a coupled Eulerian-Lagrangian method, (2008)

10. Simulia, Abaqus version 6.13-EF manual, USA, (2013)

11. A. Skzat, Scientific Letters of Rzeszow University of Technology, 25-35, 84 (2012), 